
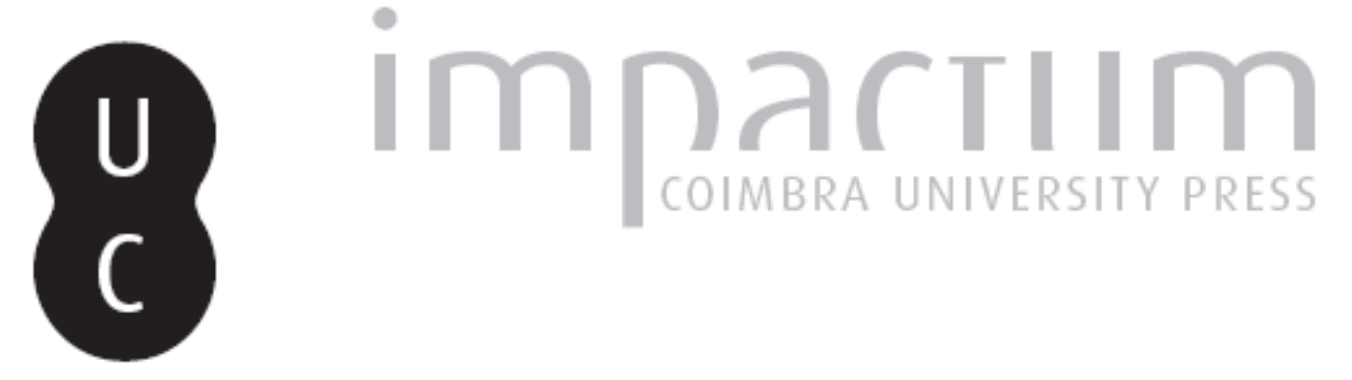

\title{
Iniciativa feminina em tempos de guerra: o epigrama XIV Page atribuído a Simónides e o testemunho de Plutarco
}

Autor(es): $\quad$ Ferreira, Luisa de Nazaré

Publicado por: International Plutarch Society

URL persistente:

URI:http://hdl.handle.net/10316.2/37638

DOI:

DOI:http://dx.doi.org/10.14195/0258-655X_5_3

Accessed : $\quad$ 26-Apr-2023 11:21:01

A navegação consulta e descarregamento dos títulos inseridos nas Bibliotecas Digitais UC Digitalis, UC Pombalina e UC Impactum, pressupõem a aceitação plena e sem reservas dos Termos e Condições de Uso destas Bibliotecas Digitais, disponíveis em https://digitalis.uc.pt/pt-pt/termos.

Conforme exposto nos referidos Termos e Condições de Uso, o descarregamento de títulos de acesso restrito requer uma licença válida de autorização devendo o utilizador aceder ao(s) documento(s) a partir de um endereço de IP da instituição detentora da supramencionada licença.

Ao utilizador é apenas permitido o descarregamento para uso pessoal, pelo que o emprego do(s) título(s) descarregado(s) para outro fim, designadamente comercial, carece de autorização do respetivo autor ou editor da obra.

Na medida em que todas as obras da UC Digitalis se encontram protegidas pelo Código do Direito de Autor e Direitos Conexos e demais legislação aplicável, toda a cópia, parcial ou total, deste documento, nos casos em que é legalmente admitida, deverá conter ou fazer-se acompanhar por este aviso.

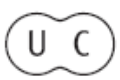




\title{
Iniciativa feminina em tempos de guerra. O epigrama XIV Page atribuído a Simonides e o testemunho de Plutarco ${ }^{1}$ por \\ Luisa de Nazaré Ferreira \\ Universidade de Coimbra \\ luisanazare@sapo.pt
}

\begin{abstract}
Abstract: Epigram XIV Page ascribed to Simonides of Ceos fixed for the posterity the Corinthian women's initiative against the Persians. This paper intends to discuss, according to Plutarch's evidence in the De Herodoti malign it ate, these women's identity and the meaning of their behaviour.
\end{abstract}

Key-Words: Plutarch, Simonides of Ceos, De Herodoti malignitate, Corinthian women.

O poeta Simonides, falando ao capitão Temistocles, um dia, em cousas de ciência praticando,

ua arte singular lhe prometia, que então compunha, com que lhe ensinasse a se lembrar de tudo o que fazia.

Começamos por recordar os versos iniciais da Elegia I de Camões. Inspiram-se numa anedota antiga, transmitida por Cícero, que reiterava o engenho invulgar do poeta Simonides, a quem se atribuía a descoberta de uma mnemotécnica ou "arte de recordar" ( $\mu \nu \eta \mu$ ovıки́ $\tau \dot{\varepsilon} \chi v \tau \mid)$. Como é sabido, o capitão Temistocles rejeita a oferta generosa, pedindo em troca uma "arte de esque- cer"2. A tradição pseudo-biográfica, que se desenvolve provavelmente a partir do séc. IV a.C., atribuíra a Simonides outros inventos no domínio das letras e da música e deu grande relevo a um traço de carácter: a avareza. De facto, são várias as notícias que retratam um cultor das Musas ávido de dinheiro e pragmático ao ponto de usar a sua sophia em proveito próprio. Se, como se pensa, esta imagem começou a circular

1 Ao Prof. Doutor José Ribeiro Ferreira agradecemos a orientação e discussão deste estudo que apresentámos no VI Congresso de Estudos Clássicos: Identidade e Cidadania Da Antiguidade aos nossos dias, promovido pela Associação Portuguesa de Estudos Clássicos e pelo Centro de História da Cultura da Faculdade de Ciências Sociais e Humanas da Universidade Nova de Lisboa (Lisboa, 18 a 21 de Outubro de 2006).

2 Cic. de Orat. 2.74.299, 86.351; Fin. 2.32.104. A invenção, por Simónides, de uma mnemotécnica é referida em várias fontes, desde o Marmor Parium (séc. III a.C.) à Suda (séc. X A.D.). 
quando ainda era vivo, possivelmente sugerida por uma nova concepção do ofício poético, os fragmentos que nos chegaram explicam por que razão foi considerado, em toda a Antiguidade, um poeta extraordinário e um guia moral, com um talento único para se expressar numa linguagem simples, precisa, com grande economia de palavras. Este estilo, que adoptou quer nas composições líricas quer nas elegíacas, é uma das principais exigências do epigrama, i.e., da inscrição gravada sobre um monumento. Não é de estranhar, por isso, que tenha sido um dos cultores mais exímios dessa forma poética, como pensavam os Antigos.

Esta reputação influenciou certamente o estabelecimento do corpus epigramático de Simonides, que inclui hoje mais de oitenta composições. Uma boa parte, porém, não lhe pertence, porque diz respeito a acontecimentos ocorridos depois da sua morte, que a tradição situa em 468 a.C. Uma outra série foi decerto composta na época helenística, pois evidencia os traços típicos dos exercícios literários ${ }^{3}$. Neste vasto conjunto distinguem-se os epigramas relativos ao conflito que, no princípio do séc. $\mathrm{V}$, opôs Helenos e Persas, uma das temáticas mais importantes da poesia de Simonides. No entanto, a autenticidade destas composições, que foram atribuídas ao poeta pelos autores antigos ou pelos editores modernos, não é de modo nenhum segura, porque no seu tempo não era costume as inscrições incluírem o nome do autor nem há notícia de ter havido recolhas de epigramas antes do período helenístico ${ }^{4}$. Trata-se, portanto, de uma problemática sem solução à vista, que não deixa de lado a inscrição votiva que nos propomos discutir.

Tanto quanto é possível saber, os dois dísticos elegíacos haviam sido gravados no lado esquerdo de quem entrava no célebre templo de Afrodite erguido na acrópole de Corinto. Pretendia-se com esta homenagem recordar a iniciativa louvável de algumas mulheres que, em tempos de luta resistente contra o terrível avanço bárbaro, foram ao templo suplicar à deusa do amor "que se abatesse sobre os seus homens a paixão de combater os Medos pela salvação da Hélade." Estes dados, bem como o texto da inscrição, foram recolhidos da obra de Teopompo de Quios, historiador do terceiro quartel do séc. IV a.C., e citados num escólio da XIII ${ }^{a}$ Olímpica de Pindaro, a propósito da referência ao destinatário da ode, o atleta Xenofonte de Corinto.

Supõe-se que nem o historiador nem o escoliasta de Pindaro conheciam o autor da inscrição, o que não é de estranhar caso seja, como se julga, uma peça autêntica. A história das mulheres de Corinto, porém, terá sido muito célebre, segundo afirma Plutarco no tratado A malícia de Herò-

3 Cf. D. L. PAGE, 1981, pp. 119-123, 209-210.

4 Cf. A. Hauvette, 1896, p. 6; D. L. Page, 1981, pp. 120, 208. 
doto $^{5}$, que a evoca no capítulo sobre a batalha de Salamina (39.871 A-B ${ }^{6}$. Acusando o historiador de ter avaliado mal a actuação dos Corintios nas Guerras Medo-Persas, Plutarco recorda que "entre as gregas, somente as mulheres corintias proferiram aquela bela e inspirada prece, apelando à deusa que incutisse nos homens a paixão de lutar contra os bárbaros".

Este testemunho começa por sublinhar o facto de as Corintias terem tomado uma iniciativa sem paralelo na Grécia. Chama depois à atenção para a qualidade da prece, que decerto teria sido motivo de grande fama. Coincide com o escólio de Pindaro na ideia central do apelo dirigido a Afrodite: as suplicantes pedem à deusa que inspire nos homens a paixão de combater. Sente-se que há aqui uma espécie de renúncia voluntária ao amor que receberiam dos seus maridos.

Além de sugerir que Heródoto ignorou intencionalmente uma história muito con- hecida, Plutarco acrescenta que Simonides compôs a inscrição e que os dois dísticos acompanhavam a dedicatória ao templo de um conjunto escultórico em bronze que representava as suplicantes. Não sabemos se tal omissão foi, de facto, voluntária, mas talvez porque o episódio "andava nas bocas do mundo", como sublinha o escritor de Queroneia, chegaram-nos três versões da inscrição: a que foi recolhida da obra de Teopompo e citada pelo escoliasta de Pindaro, a que Plutarco transmitiu, cujas fontes não reve$\mathrm{la}^{7}$, e uma terceira, evocada por Ateneu na obra Sofistas à mesa, que também atribui a autoria a Simonides (XIII 573C-E). As três versões diferem principalmente no que respeita à escolha dos epítetos e das formas verbais. O templo de Afrodite não resistiu à destruição de Corinto pelos Romanos em 146 a. C. embora o culto à deusa não tenha cessado ${ }^{8}$. É legítimo supor, portanto, que a versão mais fidedigna seja a que remonta a Teopompo de Quios (epigr. XIV Page) ${ }^{9}$ :

Embora a autenticidade do De Herodoti malignitate tenha sido posta em causa no passado, devemos considerar a questão ultrapassada. Cf. A. HAUVETTE, 1896, p. 32, n. 2; J. ROMILly, La douceur dans lapensée grecque, Paris, 1979, ९. 301; G. LACHENAUD, 1981, pp. 114-117; A. BOWEN, 1992, pp. 2-3; S.-T. TEODORSSON, "Ethical Ehstoriography. Plutarch's Attitude to Historical Criticism", in C. SCHRADER, V. RAMÓN \& J. VELA (eds.), Plutarcoy la Historia, Zaragoza, 1997, p. 439 e $\eta .1$.

Nem a inscrição nem os testemunhos que a preservam situam cronologicamente o episódio. O argumento pan-helénico (está em causa a salvação da Hélade) e o facto de Plutarco comentar a história no capítulo sobre a batalha de Salamina sugerem o ano de 480 a.C.

Como bem notou D. L. PAGE, 1981, p. 208, o relato de Plutarco sugere que conhecia também os escritos de Teopompo, mas usou outras fontes ou não foi aquela a sua fonte directa. Praticamente nada se preservou da estrutura clássica. As ruínas deram lugar a uma basílica paleocristã no período bizantino e a uma mesquita durante a ocupação turca.

A forma transmitida pelo escoliasta de Píndaro é defendida por B. A. van Groningen, 1956, p. 21, e D. L. PAge, 1981, pp. 207-210, enquanto B. M. P. StracCA, 1985, pp. 58- 


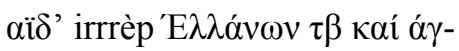

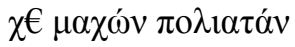

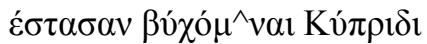

$\delta \alpha 1 \mu o ́ v i \alpha$

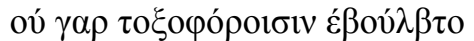

$\delta \Gamma{ }^{\prime} А \varphi \rho o \delta i ́ \tau \alpha$

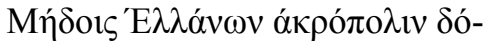

$\mu^{\wedge} v \alpha 1$.

Estas mulheres, pelos Helenos e cidadãos aliados,

dirigem a Cípris uma prece sublime, pois não era da vontade da deusa

Afrodite

aos Medos armados de arcos dar a acrópole dos Helenos.

A qualidade literária da composição e o testemunho de Plutarco levam-nos a considerar plausível a atribuição a Simonides. Sabemos, por outro lado, graças aos testimonia e aos fragmenta, que o poeta celebrou, por várias vezes, a valorosa actuação dos Coríntios nas lutas contra os Persas. Estes dados, porém, apenas dão credibilidade a uma hipótese, não a confirmam. Não é nosso desejo aprofundar esta questão nem nos vamos ocupar de aspectos de crítica textual. Pretendemos antes reflectir sobre uma outra controvérsia que tem dividido os estudiosos, pelo menos desde o final do séc. XIX: a identidade das mulheres coríntias. Sobre este ponto, a inscrição não nos dá qualquer pista. Julgamos que tanto o escoliasta de Píndaro como Plutarco se referiam às esposas dos combatentes, embora as expressões usadas não sejam esclarecedo-

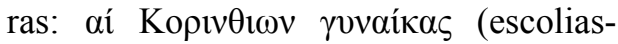

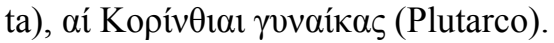

A controvérsia decorre do testemunho de Ateneu, no qual se afirma que as

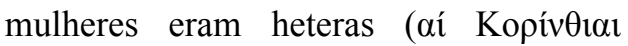

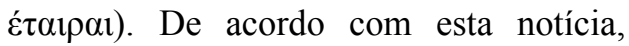
"era costume antigo em Corinto, como Cameleonte de Heracleia refere no tratado acerca de Píndaro, sempre que a pólis dirigia preces a Afrodite a respeito de assuntos graves, convocar para a oração o maior número possível de heteras; estas suplicavam à deusa e mais tarde estavam presentes nos sacrifícios.” (XIII 573C).

Note-se que enquanto Plutarco sublinha o carácter extraordinário da prece das Coríntias, fruto de uma iniciativa singular, Ateneu evoca um costume antigo, no qual a pólis assume o protagonismo. Talvez por isso, no que respeita ao sentido da súplica, apenas se diz que "as heteras coríntias foram ao templo de Afrodite e imploraram pela salvação da Hélade." (XIII 573D). Não surge, portanto, qualquer referência ao pedido de que a deusa inspirasse nos guerreiros a paixão de combater, o que até seria apropriado ao estatuto destas mulheres.

Finalmente, também não se alude à oferta de estátuas, mas fala-se de um TTÍ$v \alpha \xi$, i.e., de uma tabula ou quadro. O emprego do verbo $\gamma \rho \alpha ́ \varphi \omega$, que tanto pode

65, procura provar que a versão citada por Plutarco deve ser preferida. Para uma análise da transmissão literária da inscrição, vide ainda M. BOAS, De Epigrammatis Simonideis, Groningen, 1905, pp. 47-66. 
significar 'gravar signos, escrever' como 'desenhar, pintar', toma o passo ainda mais ambíguo, pelo que alguns estudiosos consideram que se trata de uma tábua, na qual haviam sido registados os nomes das suplicantes. Outros interpretam aqueles termos no sentido mais específico de 'pintura' ${ }^{10}$. As oferendas aos templos podiam ser muito diversas e é certo que o deíctico aï $\delta$ - 'estas mulheres' - indica que estamos perante uma inscrição votiva que acompanhava um objecto alusivo à iniciativa das Coríntias, mas tanto a escultura como a pintura têm essa função evocativa. $\mathrm{Na}$ análise deste ponto difícil de esclarecer, cremos que tem mais razão Bruna Stracca ao defender que os testemunhos de Plutarco e de Ateneu não devem ser lidos em alternativa. $O$ primeiro podia estar a referir-se à dedicatória das estátuas e o segundo apenas à tabula com a inscrição e o nome das suplicantes ${ }^{11}$.

Por aquilo que dissemos e tendo em consideração as fontes, a versão de Ateneu é a que nos merece menos credibilidade, porque além de Teopompo e do historiador Timeu de Tauroménio (séc. IV-III a.C.), começa por citar o filósofo peripatético Cameleonte de Heracleia, da segunda metade do séc. IV a.C. É provável que este estudioso tivesse tido acesso a documentos autênticos, mas nos seus escritos revela um interesse particular por anedotas ou notícias pouco fundamentadas, como se depreende dos seus comentários sobre Simónides (e.g. Ath., X 456C, XIV 656C-E). Não sabemos, porém, se Cameleonte já citava a inscrição atribuída a Simónides em abono da notícia sobre o costume antigo de Corinto ou se esse cruzamento de informações, que podem pertencer a tradições distintas, como nos parece, é da lavra de Ateneu.

Este testemunho inspira-nos alguma prudência, mas despertou o interesse de Wilamowitz, que nele baseou a tese de que as referidas cortesãs

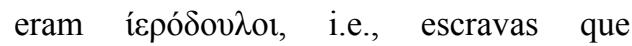
pertenciam ao templo de Afrodite, o que não é dito em nenhuma fonte. A ideia seduziu outros helenistas, como A. Hauvette (1896) e D. L. Page (1981), e foi retomada na última década do séc. XX por Christopher Brown ${ }^{13}$. Baseia-se, portanto, na certeza de que o culto coríntio incluía prostituição sagrada, uma questão que continua a dividir os estudiosos. A confirmação desta hipótese, como bem no- 
tou Walter Burkert ${ }^{14}$, reforçaria a ligação deste culto ao Oriente, já atestada por Heródoto (I 105) e, em especial, o paralelo entre Afrodite e a deusa babilónica Ishtar/Astarte ${ }^{15}$.

As fontes que nos chegaram sobre esta matéria são escassas e permitem interpretações muito díspares. $\mathrm{Na}$ época romana, Estrabão escreveu que o templo de Afrodite em Corinto fora "de tal modo rico que possuíra mais de mil escravas sagradas, heteras que haviam sido dedicadas à deusa por homens e por mulheres." (VIII 6.20). A informação refere-se a um tempo passado que não precisa e tem sido contestada por várias vozes. Diodoro Sículo (IV 83) e outro passo de Estrabão (VI 2.6) atestam a existência de escravas sagradas no santuário de Afrodite erguido no monte Erice.

Mais importante é o testemunho de Píndaro. No mesmo capítulo em que cita a inscrição atribuída a Simonides, Ateneu recorda um episódio célebre ocorrido em Corinto alguns anos depois das Guerras Medo-Persas (XIII 573E-574B). Em 464, o atleta Xenofonte prometera oferecer cem heteras ao templo de Afrodite se tivesse êxito em Olímpia. Ateneu acrescenta que Píndaro celebrou a vitória na XIII ${ }^{a}$ Olímpica e compôs também, embora com algum embaraço, a canção de mesa interpretada no banquete sacrificial, durante o qual a oferenda foi consagrada à deusa. Na opinião de alguns estudiosos, esta notícia e, em especial, os versos que preservou da composição pindárica (ff. 122 Snell-Maehler), sugerem a possibilidade de ter existido, em meados do séc. $\mathrm{V}$ a.C., prostituição sagrada em Corinto. Não podemos saber, porém, como nota J. B. Salmon, quando teria entrado essa prática no culto helénico a Afrodite $^{16}$. Os estudiosos mais cépticos chamam a atenção para o silêncio de Heródoto ${ }^{17}$ e de

14

W. BURKerT, Greek Religion: Archaic and Classical Transi, by J. RAFFAn, Cambridge, Mass., 1985 (= 1977), pp. 152-153.

15 Cf. M. L. West, The East Face of Helicon. West Asiatic Elements in Greek Poetry and Myth, Oxford, 1997, p. 56.

16 J. B. SAlmon, Wealthy Corinth. A History of the City to 338 BC, Oxford, 1984, p. 399. Na opinião de SALMON, OS versos de Píndaro atestam a existência de prostituição sagrada em Corinto (p. 399 n. 3). Cf. W. BURKERT, op. cit., ibidem.

17 A. BowEN, 1992, p. 142, em contrapartida, depreende deste silêncio que Heródoto podia ter omitido deliberadamente qualquer referência à existência de prostituição sagrada em Corinto, prática que censurava, como revela o capítulo em que descreve os cultos babilónicos em honra da deusa Ishtar (I 199). Mas, no mesmo passo, o historiador informa que havia um costume semelhante em algumas regiões de Chipre. Para um comentário ao passo de Heródoto sobre o culto a Ishtar, vide N. S. RoDRIGUES, "Economia e sociedade da Babilónia segundo os autores greco-latinos. I - O período clássico", Cadmo, 15 (2005) 47-70, especialmente pp. 58-59. 
Pausânias sobre esta matéria ${ }^{18}$, e alguns não hesitam em rejeitar categoricamente $o$ valor testemunhal do fragmento de Píndaro e da notícia de Ateneu ${ }^{19}$.

No entanto, mesmo supondo que as heteras referidas em Ateneu eram escravas sagradas, as nossas dúvidas mantêm-sese. Se a iniciativa de dirigir preces a Afrodite em favor da pólis tivesse partido das suas hierodouloi, que seriam figuras importantes em Corinto, como se explica que nem Teopompo nem Plutarco conhecessem essa tradição? Além disso, sendo devotas da deusa por excelência, a súplica estaria contemplada nas suas obrigações, pelo que não cremos que fosse considerada uma acção extraordinária.

Finalmente, como notaram alguns helenistas, não conseguimos perceber por que razão se deve rejeitar a tradição do escoliasta de Píndaro e de Plutarco, que identifica as suplicantes com as esposas dos Coríntios, sobretudo quando se reconhece que preservaram as melhores versões da inscrição atribuída a Simonides. Julgamos que esta é, de facto, a tradição mais plausível. Estas mulheres compreenderam que a queda de Corinto seria fatal para a sobrevivência da Hélade. Ao decidirem subir os 575 metros da acrópole, não se dirigiam à deusa do amor, mas à poderosa protectora da pólis, à 'Afrodite armada'20 que do alto da cidadela dominava o horizonte vasto da terra grega. Os testemunhos e a inscrição, a este respeito, não podiam ser mais claros: a prece das mulheres de Corinto não tem uma dimensão pessoal e extravasa as fronteiras do que seria

O silêncio de Pausânias é significativo, uma vez que menciona o templo de Acrocorinto e nada diz sobre a prática da prostituição sagrada. Cf. J. C. Younger, Sex in the Ancient World from $A$ to Z, London-New York, 2005, s.v. Temple (or sacred) prostitution. Este autor observa que uma interpretação alternativa do conceito de prostituição 'sagrada' seria entender o verbo $\alpha \varphi \rho \circ \delta ı \iota^{\prime} \zeta \omega$, 'fazer Afrodite', 'ter relações sexuais', no sentido de que todo o acto sexual é sagrado.

19 É esta a posição de Vinciane Pirenne-Delforge. Vide Brill s New Pauly. Encyclopaedia of the Ancient World. Vol. I, Leiden-Boston, 2002, s.v. Aphrodite, p. 832. Sobre a mesma questão, vide ainda V. PIRENNE-DELFORGE, 1994, especialmente pp. 110 sqq.

20 Cf. Paus., II 5.1. Vide o comentário ad loc. de D. Musti \& M. Torelli, 1997, pp. 233234. Outros passos de Pausânias indicam que havia estátuas de Afrodite armada em Esparta (III 15.10) e Citera (III 23.1). Quanto à interpretação desta iconografia, citamos as palavras de V. PIRENNE-DELFORGE, op. cit., p. 833: "However, this iconographical evidence can hardly be interpreted as proof that Aphrodite is a goddess of war, except in connection with the expression of the protection she affords to a people, as in Corinth,

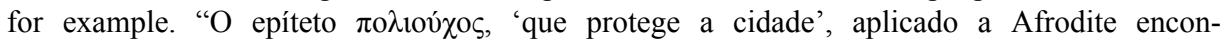
tra-se atestado no epistológrafo Alcifron (III 24.3), do séc. IV da nossa era.

21 A acrópole de Corinto era demasiado elevada. O horizonte que os olhos dali captavam era muito vasto, pelo que a posição geográfica que ocupava era considerada extraordinária. Estrabão chamou-lhe ‘o ferrolho da Grécia' (VIII 6.24). 
usual dentro da pólis. Esperar-se-ia que apelassem ao amor dos maridos para com elas e não para com a Hélade ${ }^{22}$. É uma acção de natureza cívica. No estudo que dedicou ao vocabulário grego relativo à súplica, André Corlu conclui que é limitado o número de casos referidos na literatura de pedidos aos deuses em benefício de outras pessoas e cita apenas dois exemplos de preces pela cidade ameaçada: o presente epigrama e um passo de Sete contra Tebas de Esquilo (v. 216). Numa obra mais recente sobre a súplica na religião grega, Simon Pulleyn afirma que as orações das mulheres não se diferenciavam das dos homens, mas não lhes era permitido oferecer preces pela pólis, a não ser que fossem sacerdotisas ${ }^{23}$. Teria sido essa a ousadia cometida pelas Coríntias? ${ }^{24}$ A confirmar-se esta hipótese, o êxito da luta helénica traduziu-se no elogio daquelas que, num momento de desespero, tiveram a coragem de transgredir as leis da comunidade.

Plutarco censurou Heródoto por não incluir no seu relato histórico uma tradição que, repetimos, "andava nas bocas do mundo". E certo que ele próprio não a menciona no opúsculo $A$ coragem das mulheres. Se a identidade destas Coríntias se dilui na memória dos tempos, a inscrição que procurámos discutir distingue-se no corpus epigramático de Si- mónides. É, de facto, a única que recorda um episódio de iniciativa feminina em contexto de resistência helénica contra as forças medo-persas.

\section{BIBLIOGRAFIA}

\section{Edições e comentários}

BOWEN, A.,

The Malice of Herodotus \{de Malignitate Herodoti), Warminster, 1992.

CAMPBELl, D. A.,

- Greek Lyric. Vol. Ill: Stesichorus, Ibycus, Simonides, and Others, Cambridge, Mass., 1991.

FARNELL, L. R.,

Critical Commentary to the Works of Pindar, Amsterdam, 1965 (= London, 1932).

GERBER, D. E.,

- Euterpe: An Anthology of Early Greek Lyric, Elegiac, and Iambic Poetry, Amsterdam, 1970.

GULICK, C. B.,

- Athenaeus: Deipnosophistae. Vol. VI, Cambridge, Mass., 1980.

JONES, H. L., The Geography of Strabo, Cambridge, Mass., 1927.

LACHENAUD, G,

- Plutarque. Oeuvres Morales. Tome XII', Paris, 1981.

MAEHLER, H.,

Pindarus. Pars II: Fragmenta. Indices, Leipzig, 1989.

Musti, D. \& TORELLI, M.,

- Pausania. Guida della Grécia. Libro II, Milano, ${ }^{3} 1997$.
22

23

24

ISSN 0258-655X

Cf. B. A. VAn Groningen, 1956, p. 12.

A. CORLU, Recherches sur les mots relatifs à 1'idée de prière, d'Homère aux tragiques, Paris, 1966, p. 107; S. PULleYn, Prayer in Greek Religion, Oxford, 1997, p. 169.

Sobre este ponto, cf. M. MANFREDINI, 1991, p. 585. 
PAGe, D. L.,

- Further Greek Epigrams, 1981.

PEARSON, L. \& SANDBACH, F. H.,

- Plutarch: Moralia. Vol. XI, Cambridge, Mass, 1970.

\section{Estudos}

Brown, C. G,

- "The Prayers of the Corinthian Women (Simonides, Ep. 14 Page, FGE)", GRBS, 32.1 (1991) 5-14.

FERREIRA, L. N.,

- Mobilidade poética na Grécia antiga. Uma leitura da obra de Simonides. Dissertação de Doutoramento, Faculdade de Letras da Universidade de Coimbra, 2005.

GARLAND, Y.,

- Slavery in Ancient Greece. Revised and expanded edition. Ithaca-London, 1988, pp. 112-114.

HaUvetTe, A.,

- De Vautenticité des épigrammes de Simonide, Paris, 1896.
MANFREDINI, M.,

- "Gli epigrammi del De Herodoti malignitate”, ASNP, 21 (1991) 559-590.

PIRENNE-DELFORGE, V.,

$L \backslash$ Aphrodite Grecque. Contribution à l'étude de ses cultes et de sa personnalité dans le panthéon archaique et classique, Athènes-Liège, 1994.

SALLES, C.,

- Les bas-fonds de FAntiquité, Paris, 2004 (Ia ed. 1982).

SALMON, J. B.,

Wealthy Corinth. A History of the City to 338 BC, Oxford, 1984.

STRACCA, B. M. R,

- "Lettura critica di epigrammi greci (I)", BollClass, 6 (1985) 58-75.

VAN GRONINGEN, B. A.,

- "Théopompe ou Chamaeléon? À propos de Simonide 137 B, 104 D”, Mnemosyne, 9 (1956) 11-22. 